Jurnal Ilmiah Matematika dan Pendidikan Matematika (JMP)

Vol. 12 No. 2, Desember 2020, hal. 1-13

ISSN (Cetak) : 2085-1456; ISSN (Online) : 2550-0422

\title{
PEMODELAN FAKTOR-FAKTOR YANG MEMPENGARUHI KEMATIAN IBU MELAHIRKAN DI JAWA TENGAH DENGAN ZERO INFLATED POISSON REGRESSION
}

\author{
Yusrina Ratna Annisa \\ Jurusan Matematika, Fakultas Matematika dan Ilmu Pengetahuan Alam, \\ Universitas Jenderal Soedirman \\ yusrinaratna@gmail.com
}

\section{Jajang}

Jurusan Matematika, Fakultas Matematika dan Ilmu Pengetahuan Alam, Universitas Jenderal Soedirman

\section{Agus Sugandha}

Jurusan Matematika, Fakultas Matematika dan Ilmu Pengetahuan Alam, Universitas Jenderal Soedirman

\begin{abstract}
One of the targets of the Sustainable Development Goals (SDGs) is to reduce the maternal mortality rate by 2030. In reducing the maternal mortality rate, it is necessary to first study the factors that influence it. The number of maternal mortality rate in Central Java Province in 2018 was a discrete random variable that had a Poisson distribution and had many zero values. Generally, a model was used to counting data is Poisson regression model. However, the maternal mortality that has many zero values caused overdispersion. Therefore, Poisson model was not relevant in that case. In this paper, we used Zero Inflated Poisson (ZIP) model to overcome overdispersion caused by many zero values. The results of the research show that ZIP model can explained influence the number of maternal mortality. Based on this research, the factors such as provision of $\mathrm{Fe}_{3}$ tablets, pregnant women who experience obstetric complications, and households with a clean and healthy lifestyle can explain the number of maternal mortality.
\end{abstract}

Keywords : maternal mortality, overdispersion, zero inflated poisson.

ABSTRAK. Salah satu target Sustainable Development Goals (SDGs) adalah menurunkan angka kematian ibu pada tahun 2030. Dalam menekan angka kematian ibu perlu dikaji terlebih dahulu faktor-faktor yang mempengaruhinya. Jumlah kematian ibu melahirkan di Provinsi Jawa Tengah tahun 2018 merupakan variabel acak diskrit yang berdistribusi Poisson dan memiliki banyak nilai nol. Biasanya model yang digunakan untuk data cacah adalah model regresi Poisson. Banyaknya nilai nol memunculkan overdispersi. Dengan demikian penggunaan regresi Poisson tidak relevan dalam kasus data ini. de Paper ini membahas model Zero Inflated Poisson (ZIP) dalam mengangani overdispersi akibat banyaknya nilai nol. Hasil penelitian menunjukkan bahwa model ZIP dapat menjelaskan faktor- faktor yang mempengaruhi angka kematian ibu melahirkan. Berdasarkan penelitian ini faktor-faktor seperti pemberian tablet $\mathrm{Fe}_{3}$, ibu hamil yang 
mengalami komplikasi kebidanan, dan rumah tangga berperilaku hidup bersih dan sehat dapat menjelaskan jumlah angka kematian ibu melahirkan.

Kata kunci: angka kematian ibu, overdispersi, zero inflated poisson.

\section{PENDAHULUAN}

Dalam mempercepat pembangunan manusia dan pemberantasan kemiskinan, salah satu prioritas utama bangsa Indonesia adalah pencapaian sasaran Millenium Development Goals (MDGs). MDGs atau Tujuan Pembangunan Milenium adalah deklarasi milenium hasil kesepakatan 189 negara anggota PBB yang mulai dijalankan pada September tahun 2000 yang berisi delapan butir tujuan untuk mencapai kesejahteraan rakyat dan pembangunan masyarakat, yang salah satu diantaranya adalah meningkatkan kesehatan ibu untuk mengurangi angka kematian ibu.

Angka Kematian Ibu (AKI) menjadi salah satu indikator penting dalam menentukan derajat kesehatan pada masyarakat di Indonesia. Menurut WHO kematian ibu adalah kematian selama kehamilan atau dalam periode 42 hari setelah berakhirnya kehamilan, akibat semua sebab yang terkait dengan atau diperberat oleh kehamilan atau penanganannya, tetapi bukan disebabkan oleh kecelakaan atau cedera (Kementerian Kesehatan RI, 2014: 1). Berdasarkan Survei Demografi dan Kesehatan Indonesia (SDKI) angka kematian ibu tahun 2012 sebesar 359 per 100.000 kelahiran hidup meningkat secara signifikan dibandingkan hasil SDKI tahun 2007 yaitu 228 per 100.000 kelahiran hidup (Kementerian Kesehatan RI, 2014: 1). Namun hasil Survei Antar Sensus (SUPAS) tahun 2015 menunjukkan angka kematian ibu kembali turun menjadi 305 per 100.000 kelahiran hidup (BPS, 2015: 52). Mengacu dari kondisi saat ini, target MDGs kelima dalam menurukan AKI 102 per 100.000 kelahiran hidup pada tahun 2015 belum terpenuhi. Begitupun potensi untuk mencapai target Sustainable Development Goals (SDGs) dalam jangka panjang yaitu menurunkan AKI kurang dari 70 per 100.000 kelahiran hidup pada tahun 2030 diperlukan kerja keras dan sungguh-sungguh (SDKI, 2017: 124). 
Identifikasi faktor dominan angka kematian ibu perlu dikaji, salah satu teknik untuk mencari hubungan antara angka kematian ibu dengan faktor-faktor yang mempengaruhinya dapat dikaji dengan analisis regresi. Data kasus kematian ibu di Provinsi Jawa Tengah merupakan peristiwa yang jarang terjadi atau responnya mempunyai data nol yang banyak. Kasus tersebut termasuk ke dalam ciri distribusi Poisson yaitu kejadian dengan probabilitas kecil yang terjadi pada populasi dengan jumlah anggota yang besar. Jika variabel respon yang digunakan merupakan variabel acak diskret yang berdistribusi Poisson, maka dapat digunakan model regresi Poisson untuk pembentukan model regresi nonlinier (Cameron dan Trivedi, 1998: 2). Model regresi Poisson mewajibkan kondisi equidispersi, yaitu nilai mean dan variance dari variabel respon harus memiliki nilai yang sama (Khoshgoftaar, dkk., 2004: 706). Pada kenyataannya sering ditemui data cacah dengan variance lebih besar dari pada mean atau yang sering disebut dengan overdispersi.

Menurut McCullagh dan Nelder (1989: 125), overdispersi yang disebabkan oleh banyaknya nilai nol yang berlebih pada variabel respon (excess zeros) yang terjadi karena adanya clustering dalam populasi. Adanya masalah overdispersi mengakibatkan rendah dalam mendeteksi besar pengaruh antar variabel prediktor dengan variabel respon. Salah satu metode yang digunakan dalam mengatasi masalah overdispersi adalah metode regresi Zero Inflated Poisson (Cameron dan Trivedi, 1998: 90).

Penelitian mengenai kematian ibu menggunakan regresi Zero Inflated Poisson juga pernah dilakukan oleh Sari (2016) dan Sintamulya (2017). Dalam paper ini dikaji faktor-faktor yang mempengaruhi angka kematian ibu di Jawa Tengah yaitu persentase persalinan ditolong tenaga kesehatan, persentase ibu hamil yang mendapatkan pelayanan K4 (Kunjungan kehamilan minimal 4 kali) persentase pemberian tablet $\mathrm{Fe}_{3}$ pada ibu hamil, persentase ibu hamil yang memiliki komplikasi kebidanan, persentase penduduk miskin, dan persentase rumah tangga berperilaku hidup bersih dan sehat (PHBS) dengan menggunakan regresi Zero Inflated Poisson (ZIP). Estimasi parameter yang digunakan adalah 
metode Maximum Likelihood Estimation (MLE) dan algoritma EM (Expectation Maximization) dengan pendekatan Newton-Raphson.

\section{METODE PENELITIAN}

Data yang digunakan adalah data sekunder angka kematian ibu melahirkan beserta faktor-faktor yang mempengaruhinya. Faktor-faktor tersebut adalah $X_{1}$ (persalinan ditolong tenaga kesehatan), $X_{2}$ (ibu hamil mendapat pelayanan $\mathrm{K} 4$ ), $X_{3}$ (pemberian tablet $\mathrm{Fe}_{3}$ ), $X_{4}$ (ibu hamil dengan komplikasi kebidanan), $X_{5}$ (penduduk miskin), dan $X_{6}$ (rumah tangga ber-PHBS)=1.

Analisis data dilakukan dengan bantuan software $R$ studio 3.6.0 dan IBM SPSS 20. Langkah-langkah penelitian meliputi deteksi multikolinearitas dengan Variance Inflation Factor (VIF, jika nilai $\mathrm{VIF}<10$ artinya tidak terjadi multikolinearitas) (Kutner, 2005: 409), uji distribusi Poisson, pemeriksaan overdispersi, pemodelan regresi Zero Inflated Poisson, uji kesesuaian model regresi Zero Inflated Poisson, Uji signifikansi pada model regresi Zero Inflated Poisson menggunakan uji Wald dan Menentukan model terbaik regresi Zero Inflated Poisson dengan menggunakan kriteria AIC dengan nilai AIC minimum merupakan model yang terbaik.

\section{HASIL DAN PEMBAHASAN}

\subsection{Pendeteksian Multikolinearitas}

Multikolinearitas adalah kondisi terdapatnya hubungan linier atau korelasi yang tinggi antara masing-masing variabel independen dalam model regresi. Untuk dapat menentukan apakah terdapat multikolinearitas adalah dengan melihat nilai VIF (Variance Inflation Factor). Hasil uji multikolinearitas disajikan pada Tabel 3. 
Tabel 3.1 Hasil Uji Multikolinearitas

Coefficients $^{\mathrm{a}}$

\begin{tabular}{|c|c|c|c|c|c|c|c|c|}
\hline \multirow{2}{*}{\multicolumn{2}{|c|}{ Model }} & \multicolumn{2}{|c|}{$\begin{array}{l}\text { Unstandardized } \\
\text { Coefficients } \\
\end{array}$} & \multirow{2}{*}{$\begin{array}{c}\begin{array}{c}\text { Standardized } \\
\text { Coefficients }\end{array} \\
\text { Beta }\end{array}$} & \multirow[t]{2}{*}{$\mathrm{t}$} & \multirow[t]{2}{*}{ Sig. } & \multicolumn{2}{|c|}{$\begin{array}{l}\text { Collinearity } \\
\text { Statistics }\end{array}$} \\
\hline & & B & $\begin{array}{l}\text { Std. } \\
\text { Error }\end{array}$ & & & & $\begin{array}{c}\text { Toleran } \\
\text { ce }\end{array}$ & VIF \\
\hline \multirow{7}{*}{1} & $\begin{array}{l}\text { (Cons } \\
\text { tant) }\end{array}$ & 18.739 & 24.294 & & .771 & .447 & & \\
\hline & X1 & -.089 & .230 & -.068 & -.386 & .702 & .896 & 1.116 \\
\hline & $\mathrm{X} 2$ & .127 & .131 & .197 & .968 & .341 & .673 & 1.486 \\
\hline & $\mathrm{X} 3$ & -.137 & .077 & -.358 & -1.767 & .088 & .680 & 1.471 \\
\hline & $\mathrm{X} 4$ & .026 & .061 & .078 & .425 & .674 & .838 & 1.193 \\
\hline & X5 & -.134 & .121 & -.221 & -1.112 & .276 & .705 & 1.418 \\
\hline & X6 & -.078 & .043 & -.352 & -1.810 & .081 & .737 & 1.356 \\
\hline
\end{tabular}

a. Dependent Variable: Y

Berdasarkan nilai masing-masing VIF variabel $X_{1}=1,116, X_{2}=1.486$, $X_{3}=1.471, X_{4}=1.193, X_{5}=1.418$, dan $X_{6}=1.356$. Secara keseluruhan diperoleh nilai yang kurang dari 10, sehingga dapat disimpulkan bahwa tidak ada multikolinearitas antar variabel independen tersebut.

\subsection{Pengujian Distribusi Poisson}

Pengujian distribusi Poisson pada variabel respon $\mathrm{Y}$ yaitu Angka Kematian Ibu Melahirkan dilakukan dengan menggunakan uji KolmogorovSmirnov. Tahapan uji Kolmogorov-Smirnov (D) yaitu:

Tabel 3.2 Hasil Uji Kolmogorov-Smirnov

\begin{tabular}{|ll|r|}
\hline & & \multicolumn{1}{|c|}{$\mathrm{Y}$} \\
\hline $\mathrm{N}$ & & 35 \\
Poisson Parametera,b & Mean & 2.09 \\
& Absolute & .219 \\
Most Extreme Differences & Positive & .219 \\
& Negative & -.111 \\
Kolmogorov-Smirnov Z & & 1.293 \\
Asymp. Sig. (2-tailed) & & .070 \\
\hline
\end{tabular}


Berdasarkan Tabel 3.2 diperoleh nilai Asymp. Sig. $(2$-tailed $)=0.070>$ $\alpha=0.05$, maka $H_{0}$ diterima. Dapat disimpulkan bahwa Variabel respon Y untuk angka kematian ibu melahirkan di Jawa Tengah berdistribusi Poisson.

\subsection{Model Regresi Poisson}

Model regresi Poisson untuk angka kematian ibu melahirkan di Provinsi Jawa Tengah dilakukan menggunakan program $R$ Studio 3.6.1 dapat dilihat pada Tabel 3.3.

Tabel 3.3 Estimasi Parameter Model Regresi Poisson

\begin{tabular}{lrrrl}
\hline & Estimate & Std. Error & $\mathrm{z}$ value & $\operatorname{Pr}(>|\mathrm{z}|)$ \\
\hline (Intercept) & 11.42249 & 7,80628 & 1,463 & 0,14340 \\
$X_{1}$ & $-0,07039$ & 0,07341 & $-0,959$ & 0,33764 \\
$X_{2}$ & 0,05301 & 0,04087 & 1,297 & 0,19456 \\
$X_{3}$ & $-0,05435$ & 0,01986 & $-2,737$ & $0,00621 * *$ \\
$X_{4}$ & 0,01586 & 0,02123 & 0,747 & 0,45505 \\
$X_{5}$ & $-0,07303$ & 0,04281 & $-1,706$ & $0,08803$. \\
$X_{6}$ & $-0,04205$ & 0,01508 & $-2,788$ & $0,00531 * *$ \\
\hline
\end{tabular}

Berdasarkan Tabel 3.3 dapat dilihat variabel yang signifikan terhadap model regresi Poisson adalah variabel $X_{3}=0,00621$ dan $X_{6}=0,00531$ dimana nilai keduanya $<\alpha=0,05$. Maka model regresi Poisson yang terbentuk untuk data angka kematian ibu melahirkan di Provinsi Jawa Tengah adalah :

$$
\hat{\mu}=\exp \left(-0,05435 X_{3}-0,04205 X_{6}\right) .
$$

\subsection{Pengujian Overdispersi}

Pengujian overdispersi dilakukan dengan program $R$ Studio 3.6.1 didapatkan pada Tabel 3.4 sebagai berikut. 
Tabel 3.4 Hasil uji Overdispersi

\begin{tabular}{cc}
\hline Mean & Variance \\
\hline 2,086 & 4,727731 \\
\hline
\end{tabular}

Berdasarkan Tabel 3.4 diperoleh bahwa nilai variance lebih besar dari nilai mean $(4,727731>2,086)$, maka dapat disimpulkan terjadi overdispersi. Untuk menentukan overdispersi juga dapat dilihat dari nilai pearson chi-square dan deviance residual dengan derajat bebasnya jika nilainya lebih dari 1 maka overdispersi. Berdasarkan output program $R$ Studio 3.6.1 diperoleh nilai pearson chi-square $=58.89599$ dan nilai deviance residual $=69.129$ dengan derajat kebebasan (df) adalah 28. Nilai Pearson chi-square/df $(58,89599 \div 28)$ adalah 2,10342821 dan deviance residual/df $(69.129 \div 28)$ adalah 2,46889286 sehingga disimpulkan mengalami overdispersi. Untuk mengatasi masalah overdispersi yaitu dengan model regresi Zero Inflated Poisson (ZIP).

\subsection{Model Regresi Zero-Inflated Poisson}

Model regresi Zero Inflated Poisson (ZIP) digunakan untuk memperbaiki model regresi Poisson yang mengalami overdispersi. Hasil model ZIP adalah sebagai berikut (Tabel 3.5)

Tabel 3.5 Parameter Model Regresi Zero Inflated Poisson

\begin{tabular}{lllll}
\hline & Estimate & Std. Error & $\mathrm{z}$ value & $\operatorname{Pr}(>|\mathrm{z}|)$ \\
\hline (Intercept) & 17,3344316 & 7,7974965 & 2,223 & $0,02621$. \\
$X_{1}$ & $-0,1529446$ & 0,0786346 & $-1,945$ & $0,05177$. \\
$X_{2}$ & 0,0287427 & 0,0398911 & 0,721 & 0,47120 \\
$X_{3}$ & $-0,0591606$ & 0,0193836 & $-2,598$ & $0,00938^{* *}$ \\
$X_{4}$ & 0,0612329 & 0,234342 & 2,613 & $0,00898 * *$ \\
$X_{5}$ & $-0,0591606$ & 0,0470435 & $-1,258$ & 0,20855 \\
$X_{6}$ & 0,0001021 & 0,174357 & 0,006 & 0,99533 \\
\hline
\end{tabular}


Zero-inflation model coefficients (binomial with logit link):

\begin{tabular}{lllll}
\hline & Estimate & Std. Error & $\mathrm{z}$ value & $\operatorname{Pr}(>|\mathrm{z}|)$ \\
\hline (Intercept) & 23,23394 & 30,53494 & 0,761 & 0,4467 \\
$X_{1}$ & $-0,33798$ & 0,27695 & $-1,220$ & 0,2223 \\
$X_{2}$ & $-0,06514$ & 0,18829 & $-0,346$ & 0,7294 \\
$X_{3}$ & $-0,01451$ & 0,13132 & $-0,110$ & 0,9120 \\
$X_{4}$ & 0,21884 & 0,11815 & 1,852 & 0,0640 \\
$X_{5}$ & $-0,07782$ & 0,26048 & $-0,299$ & 0,7651 \\
$X_{6}$ & $-0,14781$ & 0,07526 & -1.964 & $0,0495 *$ \\
\hline
\end{tabular}

Berdasakan Tabel 3.5, diperoleh model regresi Zero Inflated Poisson sebagai berikut:

1. Model data diskrit untuk $\mu$ :

$$
\begin{gathered}
\ln (\mu)=17,3344316-0,1529446 X_{1}+0,0287427 X_{2}-0,0591606 X_{3} \\
+0,0612329 X_{4}-0,0591606 X_{5}+0,0001021 X_{6}
\end{gathered}
$$

$\mu$ adalah peluang dari banyaknya angka kematian ibu melahirkan.

2. Model zero-inflation untuk $\omega$ :

$$
\begin{gathered}
\operatorname{logit}(\omega)=23,23394-0,33798 X_{1}-0,06514 X_{2}-0,01451 X_{3} \\
+0,21884 X_{4}-0,07782-0,14781 X_{6}
\end{gathered}
$$

$\omega$ adalah peluang resiko tidak terjadi kematian ibu melahirkan.

\subsection{Pengujian Kesesuaian Model Regresi Zero Inflated Poisson}

Pengujian ketepatan model regresi Zero Inflated Poisson (ZIP) adalah dengan menggunakan uji Likelihood Ratio (LR) dengan Statistik Uji

$$
G=-2 \ln \left[\frac{L_{0}}{L_{1}}\right]=-2\left(\ln L_{0}-\ln L_{1}\right)
$$

Setelah dilakukan analisis model Zero-Inflated Poisson dengan menggunakan program $R$ Studio 3.6.1, hasil output likelihood ratio test disajikan pada Tabel 3.6 seperti berikut. 
Tabel 3.6 Likelihood ratio test

\begin{tabular}{ccc}
\hline & LogLik & $\operatorname{Pr}(>$ Chisq $)$ \\
\hline$L_{1}$ & $-52,992$ & \\
$L_{0}$ & $-66,916$ & $0,005824 * *$
\end{tabular}

Berdasarkan Tabel 3.6 nilai $G_{\text {hitung }}=-2(-66,916-(-52,992))=$ 27,848 dan $p$-value 0,005824. Keputusannya adalah $H_{0}$ ditolak karena $\mathrm{G}_{\text {hitung }}=$ $27,848>\chi_{0,05 ; 12}^{2}=21,026$ atau dapat dilihat dari $p$-value $=0,005824<\alpha=$ 0,05. Karena $H_{0}$ ditolak artinya variabel prediktor persalinan ditolong tenaga kesehatan $\left(X_{1}\right)$, Ibu hamil mendapat pelayanan $\mathrm{K} 4\left(X_{2}\right)$, pemberian tablet $\mathrm{Fe}_{3}$ pada ibu hamil $\left(X_{3}\right)$, ibu hamil dengan komplikasi kebidanan $\left(X_{4}\right)$, penduduk Miskin $\left(X_{5}\right)$, dan rumah tangga ber-PHBS $\left(X_{6}\right)$ secara bersama-sama mempunyai pengaruh terhadap variabel respon angka kematian ibu melahirkan $(Y)$. Jadi model Zero Inflated Poisson dapat digunakan.

\subsection{Pengujian Signifikansi Parameter Regresi ZIP}

Uji signifikansi parameter tiap individu untuk menguji signifikansi parameter $\beta$ dapat dilihat dari hasil Tabel 3.5. Untuk $\beta_{1}, p$-value $=0,05177>$ $\alpha=0,05$ sehingga tidak ada pengaruh yang signifikan persalinan ditolong tenaga kesehatan terhadap angka kematian ibu melahirkan. Untuk $\beta_{2}$, diperoleh nilai $p$-value $=0,47120>\alpha=0,05$ sehingga tidak ada pengaruh yang signifikan Ibu hamil mendapat pelayanan K4 terhadap angka kematian ibu melahirkan. Untuk $\beta_{3}$, diperoleh $p$-value $=0,0093<\alpha=0,05$ sehingga ada pengaruh yang signifikan pemberian tablet $\mathrm{Fe}_{3}$ pada ibu hamil terhadap angka kematian ibu melahirkan. Untuk $\beta_{4}, p$-value $=0,00898<\alpha=0,05$ sehingga ada pengaruh yang signifikan antara ibu hamil dengan komplikasi kebidanan terhadap angka kematian ibu melahirkan. Untuk $\beta_{5}$, diperoleh $p$-value $=0,20855>\alpha=0,05$ sehingga tidak ada pengaruh yang signifikan antara penduduk miskin terhadap angka kematian ibu melahirkan. Untuk $\beta_{6}$, diperoleh $p$-value $=0,99533>\alpha=$ 
0,05 sehingga tidak ada pengaruh yang signifikan antara rumah tangga ber-PHBS terhadap angka kematian ibu melahirkan.

Untuk menguji signifikansi parameter $\gamma$ dapat dilihat dari hasil Tabel 3.5 diperoleh untuk parameter $\gamma_{1}$, diperoleh $p$-value $=0,2223>\alpha=0,05$ sehingga tidak ada pengaruh yang signifikan antara antara persalinan ditolong tenaga kesehatan terhadap angka kematian ibu melahirkan. Untuk $\gamma_{2}, p$-value $=0,729>$ $\alpha=0,05$ sehingga tidak ada pengaruh yang signifikan antara Ibu hamil mendapat pelayanan K4 terhadap angka kematian ibu melahirkan. Untuk $\gamma_{3}, p$-value $=$ $0,9120>\alpha=0,05$ sehingga tidak ada pengaruh yang signifikan antara pemberian tablet $\mathrm{Fe}_{3}$ pada ibu hamil terhadap angka kematian ibu melahirkan. Untuk $\gamma_{4}$, diperoleh $p$-value $=0,0640>\alpha=0,05$ sehingga tidak ada pengaruh yang signifikan antara ibu hamil dengan komplikasi kebidanan terhadap angka kematian ibu melahirkan. Untuk $\gamma_{5}$, diperoleh $p$-value $=0,7651>\alpha=0,05$ sehingga artinya tidak ada pengaruh yang signifikan antara penduduk miskin terhadap angka kematian ibu melahirkan. Untuk $\gamma_{6}$, diperoleh $p$-value $=0,0495<$ $\alpha=0,05$, sehingga ada pengaruh yang signifikan antara rumah tangga ber-PHBS terhadap angka kematian ibu melahirkan.

\subsection{Model Akhir Regresi Zero Inflated Poisson}

Setelah dilakukan pengujian signifikansi parameter regresi Zero-Inflated Poisson didapatkan parameter yang signifikan terhadap variabel respon $Y$ adalah $\beta_{3}, \beta_{4}$, dan $\gamma_{6}$. Berdasarkan uji parsial koefisien regresi ZIP didapatkan model akhir regresi ZIP.

Model data diskrit untuk $\mu$ adalah

$$
\ln (\mu)=17,3344316-0,0503531 X_{3}+0,0612329 X_{4}
$$

Koefisien $X_{3}$ sebesar -0,0503531 menunjukkan bahwa ibu hamil yang mendapat tablet $\mathrm{Fe}_{3}$ menurunkan resiko kematian ibu melahirkan sebesar $\exp (-0,0503531)=0,95$ kali dari pada ibu hamil yang tidak mendapatkan tablet $\mathrm{Fe}_{3}$. Koefisien $X_{4}$ sebesar 0,0612329 menunjukkan bahwa ibu hamil dengan komplikasi kebidanan meningkatkan resiko kematian ibu melahirkan 
sebesar $\exp (0,0612329)=1,06$ kali dari pada ibu hamil yang tidak mengalami komplikasi kebidanan.

Model zero inflation untuk $\omega$ adalah

$$
\operatorname{logit}(\omega)=23,23394-0,14781 X_{6} .
$$

Koefisien $X_{6}$ sebesar -0.1478 menunjukan bahwa setiap rumah tangga berperilaku hidup bersih dan sehat menurunkan resiko kematian ibu melahirkan sebesar $\exp (0,14781)=1,16$ kali dari pada rumah tangga tidak berperilaku hidup bersih dan sehat.

\subsection{Pemilihan Model Terbaik}

Nilai AIC dari masing - masing model dapat dilihat pada Tabel 3.7 berikut.

Tabel 3.7 Nilai AIC Regresi Poisson dan Regresi ZIP

\begin{tabular}{lll}
\hline & Poisson & ZIP \\
\hline AIC & 149,51 & 133,9847 \\
\hline
\end{tabular}

Berdasarkan Tabel 3.7 terlihat bahwa regresi ZIP memiliki nilai AIC terkecil yaitu 133,9847 dibandingkan dengan regresi Poisson sebesar 149,51 sehingga model terbaik adalah regresi ZIP.

\section{KESIMPULAN}

Pemodelan regresi Poisson menjelaskan hubungan angka kematian ibu melahirkan di Provinsi Jawa Tengah tahun 2018 dengan variabel prediktor pemberian tablet $\mathrm{Fe}_{3}$ pada ibu hamil dan rumah tangga ber-PHBS merupakan model yang tidak valid, karena terjadi overdispersi akibat banyak nilai nol.

Model regresi Zero-Inflated Poisson dengan memecah nilai variabel respon menjadi $y_{i}=0$ dan $y_{i}>0$. Jika $y_{i}>0$ maka akan menghasilkan count model atau $\ln (\mu)$ untuk memprediksi probabilitas data cacah dan jika $y_{i}=0$ maka akan menghasilkan zero inflated model atau logit $(\omega)$ untuk memprediksi probabilitas terjadinya zero response pada data. 
Model data diskrit untuk $\mu$ adalah

$$
\ln (\mu)=17,3344316-0,0503531 X_{3}+0,0612329 X_{4}
$$

yang berarti persentase pemberian tablet $\mathrm{Fe}_{3}\left(X_{3}\right)$ dapat menurunkan resiko kematian ibu sebesar sebesar $\exp (-0,0503531)=0,9508936$ kali dari pada ibu hamil yang tidak mendapatkan tablet $\mathrm{Fe}_{3}$. Persentase ibu hamil dengan komplikasi kebidanan $\left(X_{4}\right)$. Dapat meningkatkan resiko kematian ibu melahirkan sebesar $\exp (0,0612329)=1,06$ kali dari pada ibu hamil yang tidak mengalami komplikasi kebidanan.

Model zero inflation untuk $\omega$ adalah

$$
\operatorname{logit}(\omega)=23,23394-0,14781 X_{6}
$$

yang berarti persentase rumah tangga ber-PHBS $\left(\mathrm{X}_{6}\right)$ menurunkan resiko kematian ibu melahirkan sebesar $\exp (0,14781)=1,16$ kali dari pada rumah tangga tidak berperilaku hidup bersih dan sehat.

\section{DAFTAR PUSTAKA}

BPS, Profil Penduduk Indonesia Hasil SUPAS 2015, BPS, Jakarta, 2015.

Cameron, A. C., dan Trivedi, P. K., Regression Analysis of Count Data, Cambridge University Press, New York, 1998.

Cameron, A. C., dan Trivedi, P. K., Regression Analysis of Count Data, $2^{\text {nd }}$ Edition, Cambridge University Press, New York, 2013.

Kementerian Kesehatan RI, INFODATIN-Situasi Kesehatan Ibu, Jakarta, 2014.

Khoshgoftaar, T. M., Gao K., dan Szabo, R. M., Comparing software fault predictions of pure and zero-inflated Poisson regression models, International Journal of System Science, 36(11) (2004), 705-715.

Kutner, M. H., Nachtsheim, C. J., Neter, J., dan Li, W., Applied Linear Statistical Models, $5^{\text {th }}$ Edition, Mc-Graw-Hill Companies, New York, 2005.

McCullagh, P. dan Nelder, J. A., Generalized Linier Models, $2^{\text {nd }}$ Edition, Chapman and Hall, London, 1989.

Sari, B. K., Pemodelan Jumlah Kematian Ibu di Kota Surabaya dengan Zero Inflated Poisson Regression - Modelling The Number of Maternal 
Mortality Cases in Surabaya Using Zero Inflated Poisson

Regression, Tesis Diploma, Institut Teknologi Sepuluh Nopember, 2016.

SDKI, Survei Demografi dan Kesehatan Indonesia, Jakarta, 2017.

Sintamulya, E. A., Model regresi Zero-Inflated Poisson (ZIP) pada data overdispersi (studi kasus Data Angka Kematian Ibu Hamil di Provinsi Jawa Timur, Tesis Diploma, Universitas Negeri Malang, 2017. 